\title{
$\sqrt{\ln }$
}

\section{$32^{\text {nd }}$ International Conference on Vacuum Microbalance and Thermoanalytical Techniques (IVMTTC ${ }^{32}$ )}

June 21-24, 2009

Kazimierz Dolny, Poland

\section{Special Chapter}

\author{
Guest Editors
}

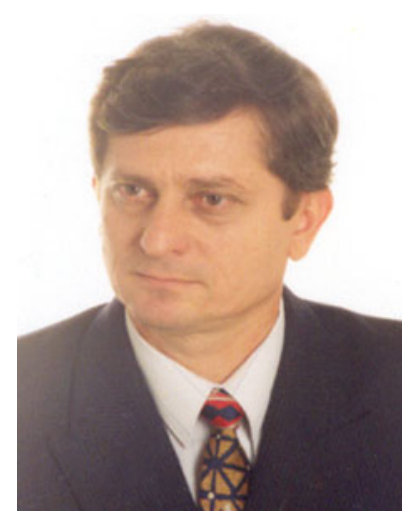

Prof. Dr. hab. Piotr Staszczuk Chair of Bionanomaterials Institute of Bionanomaterials

The John Paul II Catholic University of Lublin, Poland

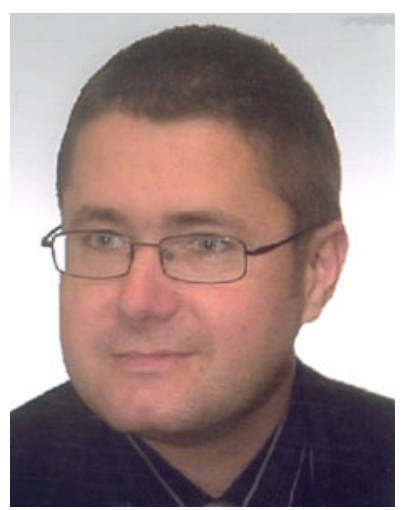

Dr. Dariusz Sternik

Department of Physicochemistry of Solid Surfaces

Maria Curie-Skłodowska University, Lublin, Poland 